\title{
'Rebirth' of a lost limb
}

\author{
Vidanapathirana $\mathbf{M}^{1}$, Sanjeewa VGM ${ }^{2}$ \\ ${ }^{\text {I} S}$ Senior Lecturer, ${ }^{2}$ Demonstrator, Department of Forensic Medicine, Faculty of Medicine, Galle.
}

e-mail address of the corresponding author,Dr.M. Vidanapathirana: mudithavidanapathirana@yahoo.co.uk

\section{Case report}

A 28 year-old machine operator working in a private company presented himself to the Department of Forensic Medicine for medico-legal examination in connection with a compensation trial. According to him, in January 2008, while he was standing by the side of the road, he was knocked down by a lorry and his right upper limb had been crushed between the lorry and a lamp post. Unexpectedly, he noticed that his right upper limb was lying by the side of the road about foot away. In spite of all this, he has had courage and ability to lift up his own amputated upper limb by himself and immediately hand it over to a bystander, who managed to bring it to Teaching Hospital Karapitiya (THK) in a bag containing ice, along with the victim. He was found to be having total traumatic amputation of the right upper limb at the level of the upper $1 / 3^{\text {rd }}$ of the arm.

Re-implantation of the right upper limb was performed by a team of surgeons (Figure 1). Humerus was fixed with two pins and vascular continuity was achieved with reverse saphenous vein graft. Strict Intensive Care (ICU) was given for 5 days. He was discharged after 6 weeks of hospitalization and was reviewed frequently at the same unit.

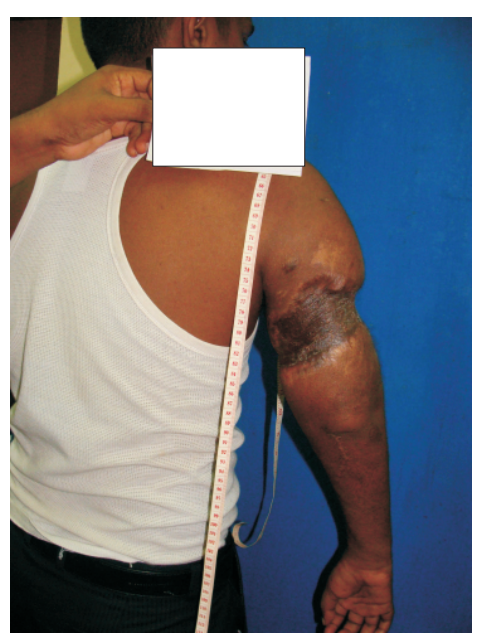

Figure 1 - Re-implanted right upper limb
He was readmitted and a skin graft was done and later one of the pins was removed. After 3 months, he was re-admitted to the same ward and a nerve graft was performed by the surgical team which included a Plastic Surgeon. Right median and ulnar nerves were grafted by using bilateral sural nerves from lower limbs. He was closely followed up at the physiotherapy and rehabilitation unit of THK.

The Occupational therapy unit at the National Hospital Colombo offered him a splint to maintain his palm at neutral position with fingers-free, thumb abducted and extended position to achieve certain degree of movement.

Now he complains of shortening of the right upper limb, wasting of right forearm and disfiguration. On observation right upper arm found to be deformed with a splint fixed to the forearm.

On examination, an irregular, large, hyperpigmented, depressed, deep scar, $27 \mathrm{~cm} \times 18 \mathrm{~cm}$ around the upper two thirds of the right arm was found. Movements of right shoulder, elbow and wrist joint were restricted. The limb length is two centimetres shorter when compared to left upper limb. The radial pulse was weak and brachial pulse could not be felt.

Mid forearm circumference was $3 \mathrm{~cm}$ lesser when compared to the left. All movements were lost in the thumb. Flexion of metacarpo-phalangeal joints were restricted and movements at proximal and distal inter phalangeal joints were absent. Examination of the motor system revealed that power was grade 3 . Reflexes and sensation were diminished.

\section{Discussion}

This is truly a surgical achievement with multidisciplinary approach. In this particular incident, patient's alertness to appropriately transport the severed limb and instant transportation 
of the amputated limb wrapped in ice should be commended and public should be made aware of this aspect during accidents.

Resultant euphoria in the victim, among hospital staff and public alone is in appreciation of the effort of everybody involved in this feat. Satisfaction of the victim is at the helm. This re-implantation should be regarded as a forerunner in addressing trauma amputations.

Re-implantation revascularization of the upper limb proximal to the elbow represents an absolute indication in specific conditions. In the young subject, in good general conditions with a clean amputation (guillotine-like caused by a circular saw), the limb preserved in ideal conditions, indications for re-implantation are supported by the expectations of good functional recovery. When amputation is due to avulsion tear the possibility of anatomical and functional success is influenced by the complexity of vascular and nervous lesions ${ }^{1}$.
Can further improvement of the condition be expected? Usual regeneration of nerves following Wallerian degeneration due to this kind of injury is evident in this case and can be expected to occur. Physiotherapy and rehabilitation are going to be important. Occupational therapy too could be important.

\section{References}

1. Bignardi A, et al. Re-implantation of the upper limb after tear lesion: long-term results. La Chirurgia degli organi di movimento, 1997 Oct-Dec; vol 82(issue 4): 409-12. (http://www.find-health-articles.com/rec_pub_9618979 Accessed on 06.07.2009)

2. Ganong WF, Review of Medical Physiology, $22^{\text {nd }}$ Ed, Tata McGraw-Hill, New Delhi: 2008; 119. 